\title{
Effect of pelvic floor muscle training on labour and newborn outcomes: a randomized controlled trial
}

\author{
Efeitos do treinamento da musculatura do assoalho pélvico sobre \\ o parto e recém-nascido: estudo controlado randomizado
}

Letícia A. R. Dias', Patricia Driusso², Daniella L. C. C. Aita ${ }^{3}$, Silvana M. Quintana ${ }^{3}$, Kari Bø $\varnothing^{4}$, Cristine H. J. Ferreira

\begin{abstract}
Background: The use of the pelvic floor muscle training for urinary incontinence treatment is well established but little is known about its effects in labor and newborn outcomes. Objectives: To evaluate the effects of antenatal pelvic floor muscle training and strength in labor and newborn outcomes in low-income pregnant women. Methods: This is a randomized controlled trial that recruited forty-two nulliparous healthy pregnant women aged between 18-36 years old and able to contract the pelvic floor muscles. The participants were included in the study with 20 weeks of gestational age and had their pelvic floor muscles measured by vaginal squeeze pressure. They were randomly allocated into two groups: training group and a non-intervention control group. Then, all participants had their labor and newborn outcomes evaluated through consultation of medical records by a blinded researcher. Results: There were no statistically significant differences between the groups regarding gestational age at birth, type of labor, duration of the second stage of labor, total time of labor, prevalence of laceration, weight and size of the baby, and Apgar score. No correlation was observed between pelvic floor muscle strength and the second stage or the total length of labor. Conclusions: This randomized controlled trial did not find any effect of pelvic floor muscle training or pelvic floor muscle strength on labor and newborn outcomes.
\end{abstract} Article registered in the Australian New Zeeland Clinical Trials Registry (ANZCTR) under number ACTRN 12609001005246

Keywords: labor; newborn; pelvic floor; muscle training; physical therapy; randomized controlled trial.

\section{Resumo}

Contextualização: O treinamento da musculatura do assoalho pélvico para tratamento da incontinência urinária é bem estabelecida, mas pouco se sabe sobre seus efeitos sobre o parto e o recém-nascido. Objetivos: Avaliar se os desfechos do parto e os resultados dos recém-nascidos são influenciados pelo treinamento e força da musculatura do assoalho pélvico realizados por gestantes de baixa renda. Métodos: Trata-se de um ensaio clínico randomizado que incluiu 42 gestantes nulíparas de baixo risco, com idade entre 18 e 36 anos, e que eram capazes de contrair a musculatura do assoalho pélvico. As gestantes foram incluídas no estudo com 20 semanas de idade gestacional, e realizava-se a avaliação da pressão de contração vaginal pela contração da musculatura do assoalho pélvico. Elas foram randomizadas em dois grupos: grupo de treinamento e grupo controle. Todas as voluntárias tiveram o trabalho de parto e os resultados dos recém-nascidos avaliados por meio de consulta ao prontuário por um pesquisador não envolvido com o grupo de treinamento. Resultados: Não houve diferença significativa entre os grupos quanto à idade gestacional no nascimento, tipo de parto, duração da segunda fase de trabalho de parto, tempo total de trabalho de parto, prevalência da laceração perineal, peso e tamanho do bebê e índice de Apgar. Nenhuma correlação foi encontrada entre a força muscular do assoalho pélvico e a segunda fase ou a duração total do trabalho de parto. Conclusões: Este ensaio clínico randomizado não verificou qualquer influência do treinamento muscular do assoalho pélvico e da força dos músculos do assoalho pélvico sobre o trabalho de parto e os resultados do recém-nascido. Artigo registrado no Australian New Zeeland Clinical Trials Registry (ANZCTR) sob o número ACTRN 12609001005246.

Palavras-chave: parto; recém-nascido; assoalho pélvico; treinamento muscular; fisioterapia; estudo controlado randomizado.

\section{Received: 07/05/2011 - Revised: 07/07/2011 - Accepted: 07/11/2011}

${ }^{1}$ Department of Biomechanics, Medicine and Rehabilitation of the Locomotor Apparatus, Faculdade de Medicina de Ribeirão Preto (FMRP), Universidade de São Paulo (USP), Ribeirão Preto, SP, Brazil

2 Physical Therapy Department, Universidade Federal de São Carlos (UFSCar), São Carlos, SP, Brazil

${ }^{3}$ Department of Obstetrics and Gynecology, FMRP, USP

${ }^{4}$ Department of Sports Medicine, Norwegian School of Sport Sciences, Oslo, Norway

Correspondence to: Cristine Homsi Jorge Ferreira, Curso de fisioterapia, Departamento de biomecânica, medicina e reabilitação do aparelho locomotor, FMRP, USP, Av. Bandeirantes, 3900, CEP 14049900, Ribeirão Preto, SP, Brasil, e-mail: cristine@fmrp.usp.br 


\section{Introduction $: \because 8$}

Pregnancy is a period that predisposes urinary incontinence with prevalence rates ranging from 23 to $67 \%^{1,2}$. A recent Cochrane review evaluating the effect of pelvic floor muscles training in incontinence concluded that nulliparous pregnant women who perform pelvic floor muscle training report less urinary incontinence during pregnancy ${ }^{3}$. However, some authors have suggested that strength training of the pelvic floor muscles may lead to obstruction of the birth canal due to muscle hypertrophy $y^{4.5}$; on the other hand, others have suggested that antenatal pelvic floor muscle training may improve flexibility, strength and motor control, facilitating the second stage of labor and reducing the need for instrumented delivery $\mathrm{y}^{4,6,7}$.

Extensive literature review revealed only two secondary analyses of randomized controlled trials on birth outcome. One study did not observe any influence of pelvic floor muscle training on duration of the first and second stage of labor, number of complications or need for instrumental delivery ${ }^{4}$. In contrast, Salvesen and Mørkved ${ }^{6}$ reported that fewer women in the training group had prolonged second stage of labor compared to the control group, this randomized controlled trial included groups of high socio-economic status only, and did not report the effect of pelvic floor muscle strength on labor and birth outcomes.

Brazil is a country with an enormous diversity in terms of socio-economical and educational status. The state of São Paulo is the wealthiest in Brazil and generates $31 \%$ of the national gross internal product ${ }^{8}$. However, the poverty rate in this state is still $26.6 \%^{9}$. In Brazil the public health system provide services to almost all low-income population, defined as annual income of less than US\$10,000.00 ${ }^{10}$. Low income pregnant women have higher rates of preterm labor, lower weight of the newborn and higher maternal mortality compared to women with a higher economic level ${ }^{11-13}$. To date there is no information whether pelvic floor muscle training during pregnancy gives additional risks to low-income pregnant women. Therefore, this study aimed to evaluate the effects of pelvic floor muscle training during pregnancy and preterm pelvic floor muscle strength in labor and delivery outcomes in low-income pregnant women.

\section{Methods $: \because$.}

\section{Design and participants}

This is an assessor-blinded randomized controlled trial that was conducted at the Hospital das Clínicas, Faculdade de
Medicina de Ribeirão Preto, Universidade de São Paulo (USP), Ribeirão Preto, SP, Brazil.

A simple randomization procedure generated by a computer random table list was used to allocate the participants to either training or control groups. A secretary who was not involved in recruitment, training or assessment of the outcome measures kept the list. The assessors of all outcome measures were blinded to group allocation. The allocation of the participants into the groups was concealed by using consecutive sealed opaque envelopes patients allocated to the intervention group received pelvic floor muscle training for 16 weeks (i.e., from week 20 to 36 of gestation). Pelvic floor muscle strength was evaluated at 20 and 36 weeks of gestation and labor and newborn outcomes were assessed from the birth registry after delivery.

\section{Participants, therapists and centers}

Pregnant women were included if they were healthy, nulliparous, carrying a single fetus, literate and older than 18 yearsold, with a gestational age of less than 20 weeks at the time of recruitment and receiving care from the Brazilian Public Health System and per capita income less than US $\$ 10000.00$ per year.

They were excluded from the study if they were unable to perform a correct pelvic floor muscle contraction, defined as an inward lift and squeeze by vaginal palpation ${ }^{14}$, reporting pain or discomfort during the exam or having any other complication during pregnancy.

Four physical therapists, with at least two years experience in assessment and training of the pelvic floor muscles participated in this study. They had postgraduate qualifications in physical therapy in women's health including specific skills to work with pelvic floor muscle training during pregnancy.

The study was approved by the Research Ethics Committee (9528/2006), of the USP. Patients from the community were recruited from advertisements that were posted in 35 health care units in the city of Ribeirão Preto. Nurses from each health care unit listed all pregnant women who satisfied the inclusion criteria. Then, a research assistant contacted these women, explained the purpose of the study and invited all of them to participate in a session with a physical therapists for the evaluation of their ability to contract the pelvic floor muscles. During this session, the women were instructed about the anatomy of the pelvic floor muscles and how to perform a correct contraction. Those presenting a score of 1 or more on the modified Oxford scale ${ }^{15}$ were included. The pelvic floor muscle strength was evaluated with vaginal squeeze pressure. After giving written informed consent, the women were randomly allocated to the intervention groups. 


\section{Intervention}

\section{Training group}

Participants allocated to the training group performed individual sessions of pelvic floor muscle training supervised by two experienced women's health physical therapists for 30 minutes on a weekly basis. The pelvic floor muscle training consisted of four sets of ten pelvic floor muscle contractions sustained for six to eight seconds with an interval of six seconds between each contraction. Three additional fast contractions ( 1 second) were performed at the end of the ten repetitions. A 30-second rest interval was defined between each set. The sets were performed with the patient in left lateral decubitus position, sitting, kneeling and standing ${ }^{16}$. During the session the physical therapists stood by the woman encouraging maximum pelvic floor muscle contractions without using accessory muscles. All participants in the training group were instructed to perform the same pelvic floor muscle training protocol at home at least twice a day. The frequency of home training was recorded in an exercise diary and collected by the physical therapists during the individual weekly sessions.

\section{Control group}

The participants allocated to the control group were not given any instruction with regards to pelvic floor muscle training, following the usual Brazilian care, which instructions regarding pelvic floor muscle training are not part of prenatal care routine ${ }^{17}$.

\section{Outcome measures}

The primary outcome measures were labor and newborn outcomes collected from medical records after delivery. A research assistant not involved with the randomization procedures or supervising of the patients collected the data. The following data were obtained from the medical records: gestational age at delivery (weeks), type of delivery, indication for caesarean section, duration of the second stage of labor (minutes), total duration of labor (minutes), prevalence and degree of laceration, and data regarding gender, weight (g), length $(\mathrm{cm})$ and Apgar scores of the newborn. The period from total cervix dilatation to the exit of the newborn was considered to be the second stage of labor ${ }^{4}$. The period from admission of the pregnant woman to the delivery room to the end of delivery, i.e. to placental expulsion and episiorraphy in the presence of episiotomy or pelvic floor muscle laceration was considered to be the total time of delivery. When delivery was performed by caesarean section, suture of the surgical incision was considered to be the end of delivery as described in the medical records.
The secondary outcome measure was pelvic floor muscle strength evaluated at 20 and 36 weeks of gestation. Pelvic floor muscle strength was measured by vaginal squeeze pressure during maximum voluntary contraction using Peritron ${ }^{\circledR}$. Peritron ${ }^{\circledR}$ has been found to have good intra and inter-tester reliability ${ }^{18,19}$. The device was calibrated to zero before each measurement. The women were instructed to undertake 3 maximum pelvic floor muscle contractions with a rest interval of 30 seconds between each contraction. Each contraction was held for 5 seconds. The mean value of the three contractions was used for the analysis. Only contractions with visible observation of the perineum and probe getting inward were considered valid ${ }^{20}$. Co-contraction of the gluteal and hip adductor muscles was discouraged ${ }^{19}$.

At 36 weeks of gestation, women allocated to the training group completed an anonymous questionnaire containing questions about the training program. The women were allowed to complete the questionnaire in private with no interference by the investigators. The questionnaire was returned folded to a member of the team.

\section{Data analysis}

The demographic variables of the participants and data related to type of labor was compared using the Fisher exact test. All between-groups comparisons were performed following intention-to-treat principles ${ }^{21}$. Analysis of variance (ANOVA) was used to calculate the between-groups differences for the following outcomes: labor delivery, newborn variables, pelvic floor muscle strength at 36 weeks of gestation and between mean pelvic floor muscle strength with 36 weeks of gestation and type of delivery. For the correlation between mean pelvic floor muscle strength and second stage and total length of labor the Pearson correlation coefficient was used. Significance level was set to $5 \%$.

\section{Results $: \because$.}

From January 2007 to November 2008, 67 healthy primiparous women were invited to participate in the study. Of these, 42 fulfilled the inclusion criteria, and were randomly allocated into the training group $(\mathrm{n}=21)$ or control group $(n=21)$. At 36 weeks of gestation, strength data of 5 women of the training group and 4 women of the control group were lost for follow-up. Reasons for loss for follow-up are listed in Figure 1.

Baseline characteristics of the participants are shown in Table 1. There were no statistically or clinically importantly significant differences between the two study groups at baseline. 
The mean attendance of the training group in a total of 16 programmed supervised sessions was 12.61 (SD 5.5) out of 16 possible training sessions. Seventeen out of the 21 participants in the training group (81\%) attended at least 12 (75\%) of weekly sessions of supervised training. No adverse effects were reported by the participants.
The results on type of labor are presented in Table 1. There were no statistically significant differences between the two groups ( $\mathrm{p}=0.35$ ). All perineal lacerations of the pelvic floor muscle were $1^{\text {st }}$ degree in both groups with no between-group differences being observed $(p=0.66)$. The indications for caesarean section were: acute fetal suffering $(n=11)$, ephalopelvic

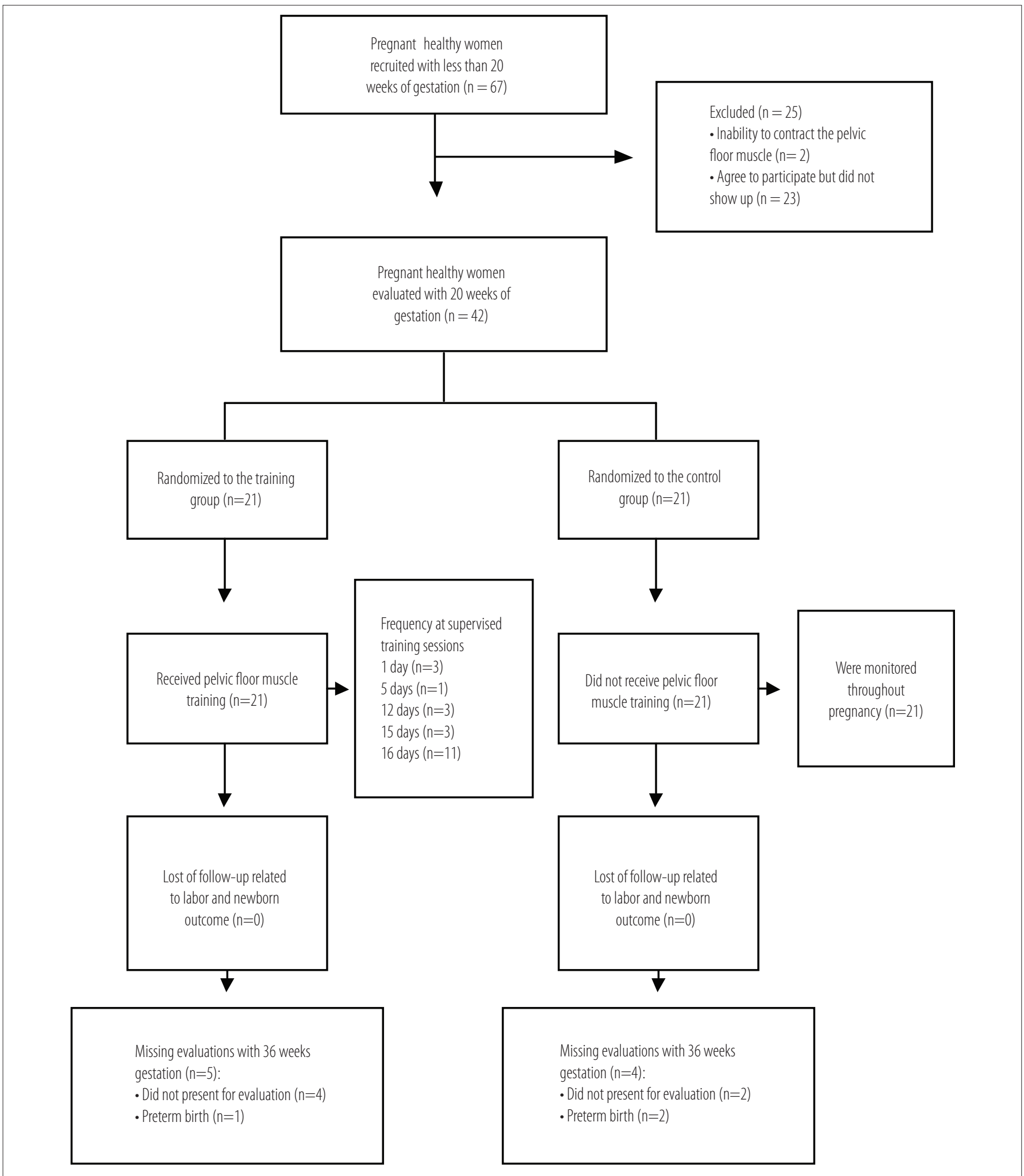

Figure 1. Design and flow of participants through the trial. 
disproportion $(n=4)$, cord prolapse, secondary $(n=2)$ arrest of dilation $(n=1)$ and fetal tachycardia $(n=1)$. Some participants had more than one indication for the caesarean section. Table 2 lists the mean values of the delivery and newborn data for the control group and training group. There were no between-group statistically significant differences in any of the variables.

Table 3 shows no difference in mean pelvic floor muscle strength between those who had vaginal delivery without

Table 1. Characteristics of participants.

\begin{tabular}{|c|c|c|c|}
\hline Characteristics & $\begin{array}{l}\text { Training group } \\
\qquad n=21\end{array}$ & $\begin{array}{l}\text { Control group } \\
\qquad n=21\end{array}$ & $p$ value \\
\hline BMI $\left(\mathrm{Kg} / \mathrm{m}^{2}\right)$ mean $(\mathrm{SD})$ & $23.8(3.8)$ & $25.2(5.3)$ & 0.85 \\
\hline Age (years) mean (SD) & $23.1(5.1)$ & $23.7(4.8)$ & 0.99 \\
\hline Race n (\%) & & & 0.99 \\
\hline White & $13(62)$ & $12(57)$ & \\
\hline Nonwhite & $8(38)$ & $9(43)$ & \\
\hline Marital status, n (\%) & & & 0.82 \\
\hline Single & $11(52)$ & $11(52)$ & \\
\hline Living together & $4(19)$ & $3(14)$ & \\
\hline Married & $6(29)$ & $7(34)$ & \\
\hline Maternal Education, n (\%) & & & 0.18 \\
\hline$<$ High school & $6(29)$ & $0(0)$ & \\
\hline High school & $13(62)$ & $18(86)$ & \\
\hline$>$ High school & $2(9)$ & $3(14)$ & \\
\hline Type of delivery & & & 0.35 \\
\hline Vaginal, n (\%) & $5(24)$ & $2(9)$ & \\
\hline Vaginal with episiotomy, n (\%) & $8(38)$ & $5(24)$ & \\
\hline Forceps, $n(\%)$ & $3(14)$ & $4(19)$ & \\
\hline Caesarean, n (\%) & $5(24)$ & $10(48)$ & \\
\hline Perineal laceration, n (\%) & $5(24)$ & $2(9)$ & 0.66 \\
\hline $\begin{array}{l}\text { Pelvic floor strength }\left(\mathrm{cmH}_{2} 0\right) \\
\text { at } 20 \text { weeks mean }(\mathrm{SD})\end{array}$ & $28.2(14.9)$ & $33.7(20.3)$ & 0.16 \\
\hline
\end{tabular}

episiotomy, vaginal delivery with episiotomy or forceps delivery. There was not a statistical difference in mean pelvic floor muscle strength between those who had vaginal delivery (without episiotomy or forceps) and caesarean section, with women who underwent caesarean section having stronger pelvic floor muscle. A statistical significant difference in mean pelvic floor muscle strength was found between the women who had vaginal delivery with episiotomy and caesarean section $(\mathrm{p}=0.02)$ and between forceps delivery and caesarean section $(p=0.04)$, with stronger pelvic floor muscle in the caesarean section group.

The correlation between mean pelvic floor muscle strength at 36 weeks gestation and second stage length of labor was 0.25 (95\% CI: -0.21 to 0.62 ) and between mean of pelvic floor at 36 weeks gestation and total length of labor was -0.14 (95\% CI: -0.46 to 0.21 ).

\section{Discussion $\because \because$.}

The results of this randomized controlled trial showed that there was no difference between the training group and control group regarding labor or newborn outcomes. Similarly, no correlation was found between pelvic floor muscle strength and the second stage or the total length of labor.

No difference was found in gestational age of the participants in the training group and control group at the time of delivery. In the randomized controlled trial performed by Salvesen and Mørkved ${ }^{6}$ there was a small difference in days of gestational age between the control group and training group $(\mathrm{p}=0.04)$, with training group having a shorter

Table 2. Comparison of labor, delivery, and newborn variables between the training and control groups.

\begin{tabular}{|c|c|c|c|c|c|c|c|}
\hline \multirow{2}{*}{ Outcomes } & \multicolumn{2}{|c|}{ Training group } & \multicolumn{2}{|c|}{ Control group } & \multirow{2}{*}{ Between-group differences } & \multirow{2}{*}{$95 \% \mathrm{Cl}$} & \multirow{2}{*}{$\mathrm{p}$ value } \\
\hline & Mean & SD & Mean & SD & & & \\
\hline Gestational age at delivery (weeks) & 39.5 & 1.71 & 39.3 & 1.22 & -0.17 & -1.09 to 0.76 & 0.72 \\
\hline Duration of the 2nd stage of labor * (minutes) & 21.8 & 17.6 & 41.1 & 53.5 & 0.38 & -0.33 to 1.08 & 0.28 \\
\hline Total duration * (minutes) & 233.4 & 130.9 & 258.7 & 183.7 & 0.02 & -0.41 to 0.46 & 0.91 \\
\hline Newborn weight (grams) & 3178.3 & 532.6 & 3309.0 & 524.1 & 130.71 & -198.87 to 460.30 & 0.43 \\
\hline Newborn length (cm) & 48.7 & 2.0 & 49.1 & 2.4 & 0.36 & -1.04 to 1.76 & 0.61 \\
\hline Apgar $1^{\text {st }}$ minute & 8.3 & 2.1 & 8.1 & 1.4 & 0.00 & -1.99 to 1.99 & 1.00 \\
\hline
\end{tabular}

* Logarithmic transformation was applied to the response variable.

Table 3. Comparison of mean pelvic floor muscle strength with 36 weeks of gestational age and type of delivery.

\begin{tabular}{|c|c|c|c|c|}
\hline Variables & Comparison - type of delivery & Difference between type of delivery & $95 \% \mathrm{Cl}$ & $p$ value \\
\hline \multirow[t]{6}{*}{ Mean pelvic floor muscle strength $\left(\mathrm{cmH}_{2} \mathrm{O}\right)$ * } & vaginal $x$ vaginal with episiotomy & 3.98 & -10.92 to 18.88 & 0.59 \\
\hline & vaginal $x$ forceps & 3.24 & -12.69 to 19.18 & 0.68 \\
\hline & vaginal $x$ caesarean & -11.16 & -24.79 to 2.46 & 0.10 \\
\hline & vaginal with episiotomy $x$ forceps & -0.74 & -15.64 to 14.17 & 0.92 \\
\hline & vaginal with episiotomy $\mathrm{x}$ caesarean & -15.14 & -27.55 to -2.74 & 0.02 \\
\hline & Forceps $x$ caesarean & -14.41 & -28.03 to -0.49 & 0.04 \\
\hline
\end{tabular}

\footnotetext{
* intention-to-treat analysis was used.
} 
duration of gestational age. Regarding the Apgar scores of the newborns in our study, the 1st minute values were similar for the control group and the training group. This is in agreement with data reported by Nielsen et al. ${ }^{22}$ and Salvesen and Mørkved ${ }^{6}$.

We did not find any between-group significant difference regarding duration of the second stage of labor, although the mean duration of this stage was much shorter in the training group women than in the control group women. These findings agree with data reported in the two other published randomized controlled trials ${ }^{4,6}$ and also in a quasi-randomized trial $^{22}$. However, Salvesen and Mørkved ${ }^{6}$ found a lower number of women with prolonged deliveries (>60 minutes), among women who had performed pelvic floor muscle training during pregnancy.

One possible cause of lower duration of the second stage of labor is low infant birth weight ${ }^{23}$. In the present study, mean newborn weight was not significant for both groups. However, newborn weight was within normal range in both groups. Salvesen and Mørkved ${ }^{6}$ found a lower weight in newborns from the trained group and this may have influenced their results. In contrast, Agur et al. ${ }^{4}$ detected a greater weight among newborns in their training group. Several studies indicate a relationship between low income, low birth weight and preterm delivery $y^{12,24,25}$. This is due to the fact that low-income pregnant women are more likely to receive an inadequate prenatal care, to suffer from more violence during pregnancy, to have a poor diet, a higher rate of urinary tract infection etc. Nevertheless, higher rates of low birth weight and preterm delivery were not found in the present study groups compared to the study population of the two randomized controlled trials including a sample of higher socioeconomic level ${ }^{4,6}$. A limitation in our study and the other three published intervention studies was that other variables that could have influenced the newborn weight and pre-term labor such as diet and weight gaining during pregnancy were not assessed ${ }^{4,6,22}$.

We do not found significant differences between groups in rate of vaginal delivery with and without episiotomy. Previous studies on the same topic also detected no between-group difference in type of delivery performing or not performing pelvic floor muscle training during pregnancy ${ }^{6,7,22}$. Although the World Health Organization ${ }^{26}$ recommends a rate of caesarean delivery not exceeding 15\%, caesarean deliveries in Brazil correspond to $43 \%$ of all deliveries, being more common among women of high educational level. A high rate of caesarean deliveries was observed in both groups of the present study. Although the control group had a slightly lower educational level, there was no between-group statistically significant difference in educational level. In addition, the indication for caesarean delivery recorded in the medical records was related to maternal or fetal risks in both groups.

No positive association between pelvic floor muscle strength at 36 weeks of gestation and type of delivery, duration of the second stage of labor and total duration of delivery was found. Women with caesarean section had stronger pelvic floor muscle at 36 weeks of gestational age, but a statistically significant difference was found only between caesarean section and vaginal delivery with episiotomy or forceps. To our knowledge, this is the first study reporting associations between these outcomes and actual strength using a reliable assessment tool for pelvic floor muscle strength ${ }^{18,19}$. Little is known about the influence of the morphology and function of pelvic floor muscle on variables that could influence the type of delivery. Some studies indicate that women with stress urinary incontinence and bladder neck mobility have lower pelvic floor muscle strength ${ }^{14,27}$. Others indicate that vaginal delivery is correlated with larger levator hiatus diameter and greater bladder neck mobility ${ }^{28}$. It is plausible to suggest that these women may have less pelvic floor muscle strength. However, there may also be other important factors related to facilitation of vaginal delivery such as levator ani flexibility ${ }^{29}$. Dietz, Shek and Clarke ${ }^{30}$ demonstrated with 3D ultrasound that some young nulliparous women achieved elongation of the pubovisceral muscle fibers by a factor of two with a Valsalva maneuver while others barely showed any elongation of fibers at maximal Valsalva.

Type of delivery is determined by different variables, especially in Brazil where the high rates of caesarean sections are related to many cultural aspects, making the interpretation of the influence of pelvic floor muscle training and pelvic floor muscle strength very difficult. Further research in larger samples should assess the possible association of pelvic floor muscle strength, type of delivery and the stretch capacity of the pelvic floor muscle.

The main limitations of the present study were the small sample size. The strengths of the study are the randomized controlled trial design with blinded assessors, supervised follow-up of the participants and high exercise compliance. Besides, this is the first randomized controlled trial that analyzed the influence of the pelvic floor muscle strength on labor outcome. Further studies that involve the effects of pelvic floor muscle training during pregnancy on delivery mode and pelvic floor muscle function in postpartum are urgently needed.

\section{Conclusions $: \because$.}

The results of the present study demonstrated that pelvic floor muscle training had no effects on delivery and newborn outcomes in a sample of low social economic profile women 
suggesting that recommending pelvic floor muscle training to low-income nulliparous women is safe. Further high quality randomized controlled trials of supervised and intensive pelvic floor muscle training with larger sample sizes are warranted to substantiate these findings.

\section{Acknowledgments : : :}

We would like to thank the Fundação de Amparo a Pesquisa do Estado de São Paulo (FAPESP) - process 07/50824-9 - for funding this study.

\section{References $: \because$.}

1. Chiarelli P, Brown W, McElduff P. Leaking urine: prevalence and associated factors in Australian women. Neurourol Urodyn. 1999;18(6):567-77.

2. Santos PC, Mendonça D, Alves 0 , Barbosa AM. Prevalência e impacto da incontinência urinária de stresse antes e durante a gravidez. Acta Med Port. 2006;19:349-56.

3. Hay-Smith J, Mørkved S, Fairbrother KA, Herbison GP. Pelvic floor muscle training for prevention and treatment of urinary and faecal incontinence in antenatal and postnatal women. Cochrane Database Syst Rev. 2008: CD007471.

4. Agur W, Steggles P, Waterfield M, Freeman R. Does antenatal pelvic floor muscle training affect the outcome of labour? A randomised controlled trial. Int Urogynecol J Pelvic Floor Dysfunct. 2008;19(1):85-8

5. UK Midwifery Archives. Does horse-riding affect the pelvic floor? 2000: http://www.radmid. demon.co.uk/pelvicfloor.htm: acessed November 12, 2009

6. Salvesen KA, Mørkved S. Randomised controlled trial of pelvic floor muscle training during pregnancy. BMJ. 2004;329(7462):378-80.

7. Bø K, Fleten C, Nystad W. Effect of antenatal pelvic floor muscle training on labor and birth. Obstet Gynecol. 2009;113(6):1279-84

8. Governo do Estado de São Paulo. Conheça SP: Uma potência chamada São Paulo. 2009: http:// www.saopaulo.sp.gov.br: acessed November 12, 2009.

9. Instituto Brasileiro de Geografia e Estatística - IBGE. Censo Demográfico 2000 e Pesquisa de Orçamentos Familiares. Ministério do Planejamento, Orçamento e Gestão. 2002/2003. accessed November 12, 2009. Disponível em: http://www.ibge.org.br:

10. Szanton SL, Seplaki CL, Thorpe RJ Jr, Allen JK, Fried LP. Socioeconomic status is associated with frailty the Women's Health And Aging Studies. J Epidemiol Community Health. 2010;64(1):63-7.

11. Araújo BF, Tanaka AC. Risk factors associated with very low birth weight in a low-income population. Cad Saúde Pública. 2007;23(12):2869-77.

12. Coimbra LC, Figueiredo FP, Silva AAM, Barbieri MA, Bettiol H, Caldas AJ, et al. Inadequate utilization of prenatal care in two Brazilian birth cohorts. Braz J Med Biol Res. 2007;40(9):1195-202.

13. Cruz-Anguiano V, Talavera JO, Vázquez L, Antonio A, Castellanos A, Lezana MA, et al. The importance of quality of care in perinatal mortality: a case-control study in Chiapas, Mexico. Arch Med Res. 2005;35(6):554-62

14. Thompson JA, O'Sullivan PB, Briffa NK, Neumann P. Assessment of voluntary pelvic floor muscle contraction in continent and incontinent women using transperineal ultrasound, manual muscle testing and vaginal squeeze pressure measurements. Int Urogynecol J Pelvic Floor Dysfunct. 2006;17(6):624-30

15. Laycock J. Clinical evaluation of the pelvic floor. In: Schussler B, Laycock J, Norton P, Stanton SL (Ed). Pelvic Floor Re-education. $1^{\text {a }}$ ed. London: Springer; 1994. p. 42-8.
16. Mørkved S, Bø K, Schei B, Salvesen KA. Pelvic floor muscle training during pregnancy to prevent urinary incontinence: a single-blind randomized controlled trial. Obstet Gynecol. 2003;101(2):313-9.

17. Brazilian Federation of Societies of Gynecology and Obstetrics. Projeto Diretrizes: Assistência Pré-Natal. 2001:8.

18. Frawley HC, Galea MP, Phillips BA, Sherburn M, Bø K. Reliability of pelvic floor muscle strength assessment using different test positions and tools. Neurourol Urodyn. 2006;25(3):236-42.

19. Hundley AF, Wu JM, Visco AG. A comparison of perineometer to brink score for assessment of pelvic floor muscle strength. Am J Obstet Gynecol. 2005;192(5):1583-91.

20. Bø K, Kvarstein B, Hagen RR, Larsen S, Burgio KL. Pelvic floor muscle exercise for the treatmen of female stress urinary incontinence: II. Validity of vaginal pressure measurements of pelvic floor muscle strength and the necessity of supplementary methods for control of correct contraction. Neurourol Urodyn. 1990;9(5):479-87.

21. Hollis $S$, Campbell F. What is meant by intention to treat analysis? Survey of published randomised controlled trials. BMJ. 1999;319(7211):670-4.

22. Nielsen CA, Sigsgaard I, Olsen M, Tolstrup. M, Danneskiold-Samsoee. B, Bock JE. Trainability of the pelvic floor. A prospective study during pregnancy and after delivery. Acta Obstet Gynecol Scand. 1988;67(5):437-40.

23. Badr LK, Abdallah B, Mahmoud A. Precursors of preterm birth: comparison of three ethnic groups in the Middle East and the United States. J Obstet Gynecol Neonatal Nurs. 2005;34(4):444-52.

24. Dimetry SR, El-Tokhy HM, Abdo NM, Ebrahim MA, Eissa M. Urinary tract infection and adverse outcome of pregnancy. J Egypt Public Health Assoc. 2007;82(3-4):203-18.

25. Ferri CP, Mitsuhiro SS, Barros MC, Chalem E, Guinsburg R, Patel V, et al. The impact of maternal experience of violence and common mental disorders on neonatal outcomes: a survey of adolescent mothers in Sao Paulo, Brazil. BMC Public Health. 2007;7:209.

26. Appropriate technology for birth. Lancet. 1985;2(8452):436-7.

27. Morin M, Bourbonnais D, Gravel D, Dumoulin C, Lemieux MC. Pelvic floor muscle function in continent and stress urinary incontinent women using dynamometric measurements. Neurourol Urodyn. 2004;23(7):668-74

28. Toozs-Hobson P, Balmforth J, Cardozo L, Khullar V, Athanasiou S. The effect of mode of delivery on pelvic floor functional anatomy. Int Urogynecol J Pelvic Floor Dysfunct. 2008;19(3):407-16

29. Lien KC, Mooney B, DeLancey JO, Ashton-Miller JA. Levator ani muscle stretch induced by simulated vaginal birth. Obstet Gynecol. 2004;103(1):31-40

30. Dietz HP, Shek C, Clarke B. Biometry of the pubovisceral muscle and levator hiatus by threedimensional pelvic floor ultrasound. Ultrasound Obstet Gynecol. 2005;25(6):580-5. 